\title{
Difference in prevalence of diabetes, obesity, metabolic syndrome and associated cardiovascular risk factors in a rural area of Tamil Nadu and an urban area of Delhi
}

\author{
Ranjita Misra $\cdot$ Anoop Misra $\cdot$ N Kamalamma $\cdot$ \\ Naval K. Vikram • Sunil Gupta $\cdot$ Sushum Sharma • \\ Thakor Patel $\cdot$ Padmini Balagopal
}

Received: 3 February 2010 /Accepted: 21 June 2010 /Published online: 1 April 2011

(C) Research Society for Study of Diabetes in India 2011

\begin{abstract}
This study compared difference in diabetes, obesity, metabolic syndrome (MetS), C-reactive protein (hs-CRP), homocysteine, and other cardiovascular risk factors between rural and urban Asian Indians using similar/standardized field measurements. The design used a cross-sectional and population-based study among rural (Tamil Nadu) and urban (Delhi) Asian Indians aged 18 years and older. 574 rural Indians and 508 urban Indians completed face-to-face interviews, and anthropometric measurements. Fasting venous blood samples were obtained for fasting plasma glucose and serum lipid tests. The mean age was $42.6 \pm 11.8 \mathrm{y}$ (urban) and $39.5 \pm 13.9$ y (rural). Although the prevalence of type 2
\end{abstract}

R. Misra $(\bowtie)$

Center for the Study of Health Disparities (CSHD),

Department of Health and Kinesiology, Intercollegiate Faculty

of Nutrition, Texas A\&M University College,

158V Read Building, 4243 TAMU,

College Station, TX 77843, USA

e-mail: misra@hlkn.tamu.edu

A. Misra

Fortis Hospital,

New Delhi, India

N. Kamalamma $\cdot$ P. Balagopal

Gandhigram Rural Institute,

Dindigul, Tamil Nadu, India

N. K. Vikram

All India Institute of Medical Sciences,

New Delhi, India

S. Gupta $\cdot$ S. Sharma

Railways Hospital,

New Delhi, India

T. Patel

Uniformed Services University of the Health Sciences,

Bethesda, MD, USA diabetes (T2DM) was lower in rural (8.4\%) than urban (13.6\%) areas, rural Asian Indians had a higher percent of undiagnosed cases $(25 \%)$, poorer glycemic control, and unawareness of diabetes than their urban peers. Urban Indians had elevated rates of the MetS (as defined by NCEP and IDF criteria), hs-CRP, total cholesterol, LDL, and hypertension than their rural peers. Females in general had significantly higher central obesity and lower HDL-C than males. Homocysteine levels (measured only among urban respondents) was higher among males than females $(p=.04)$. Prevalence of hypertension increased with age $(r=.37$, $p<.001)$ and correlated with respondents' blood glucose levels $(r=.11, p<.001)$. There was a step-wise worsening of risk factors as individuals progressed from normal to IFG to T2DM. High burden of diabetes and other cardiovascular risk factors in urban and rural Asian Indians provide basis for tailored and cost-effective prevention and intervention programs, in such resource-constrained settings.

Keywords Diabetes - Prevalence $\cdot$ C-reactive protein . Metabolic syndrome $\cdot$ Urban $\cdot$ Rural $\cdot$ India

\section{Background}

The burden of diabetes is more pronounced in India than any other country in the world [1]. An estimated 46.5 million Indians have diabetes (2007) with a projected increase to 80 million by 2030 [1].Type 2 diabetes mellitus (T2DM) occurs a decade earlier than in other ethnic groups and may lead to more complications [2, 3]. Increased urbanization, nutrition and lifestyle transitions are associated with the rapid rise of T2DM in urban as well as rural areas [4-6]. In particular, affluence and automation has resulted in pronounced physical inactivity and consumption of diets rich in fat, sugar and calories [7]. 
With more than a billion people, India is home to significantly diverse groups of people in terms of ethnicity, caste and religion, socioeconomic status, educational level, and lifestyle and food habits [6]. Approximately 70\% of India's population lives in rural areas and in resource-poor settings where the increasing prevalence and chronic nature of T2DM poses considerable health and economic burden [3]. Studies consistently show high rates of T2DM and the Metabolic Syndrome (MetS) and cardiovascular disease (CVD) in the Asian Indian population as compared to Caucasians and other ethnic groups [8-11]. Insulin resistance, a key pathophysiologic factor, is highly prevalent in Asian Indians, despite low rates of obesity [9, 12-14]. Impaired glucose tolerance is more common in Asian Indians at a young age. Most of the studies have been carried out on the prevalence of diabetes in urban areas [15-20] with a few in rural areas [21-23]. The study by Mahadik et al. [9] and Zargar et al. [15] examined both rural and urban populations but the former study assessed only MetS and the later was limited to Kashmir state in North India. The prevalence of diabetes in India study (PODIS) [6] is the only country-wide prevalence study on diabetes that took into account the marked heterogeneity of the Indian population.

The purpose of this population-based study was to determine the prevalence of pre-diabetes, T2DM, MetS and association with hs-CRP, homocysteine, and lipid profile in rural and urban sites in India using similar design and field measures.

\section{Methods}

Subjects

A cross-sectional and population-based study design was used among rural and urban Indians $\geq 18$ years. The period of study was 2005 to 2007 . Urban sample was selected based on multi-stage cluster sampling technique, according to the modified World Health Organization Expanded Program of Immunization Sampling Plan [24]. First, a list of residential colonies within $10 \mathrm{~km}$ of the All India Institute of Medical Sciences was prepared. Colonies were randomly selected from this list for inclusion. The number of houses in each colony was determined and the Resident Welfare Associations of these colonies were approached to conduct the study in their locality. The households were selected randomly and one member from each was invited to participate in the study. 900 urban respondents from a wide range of socioeconomic strata were contacted for participation and 610 completed the face-to-face interviews (response rate $67.7 \%)$ and $508(56.4 \%)$ completed anthropometric measurements, and provided venous blood sample after an overnight fast of at least $8 \mathrm{~h}$ for blood tests. The questionnaire (in both Hindi and English) used for the study was initially pretested in a smaller population ( $n=10$ in each site) and validated. Most of the subjects who refused to participate in Delhi did not want to spare time for the survey and blood work since they had to report to work early in morning.

In the rural site, sample was randomly selected from eight hamlets (out of 30) classified as 'rural' by the Indian government land records. 850 individuals were contacted through door-to-door visitations, 599 rural Indians participated in the face-to-face interviews by trained interviewers and 574 completed the anthropometric measurements and fasting blood work (response rate 67.5\%) at the Gandhigram Rural Institute. Most of the respondents who refused to participate in the rural areas were migrant workers. The All India Institute of Medical Sciences (AIIMS), Delhi was used for urban Indians and also served as the core laboratory for biochemical analysis. The study was approved by the Institutional Review Board of Texas A \& M University and AIIMS.

\section{Data collection}

Information was collected on demographic profile, anthropometrics, T2DM and CVD risk factors e.g., blood pressure, smoking, generalized and abdominal obesity, fasting blood glucose values, serum lipids, fasting plasma insulin, and high-sensitivity C-reactive protein (hs-CRP) levels. The primary endpoint of the study was the prevalence of diabetes, MetS, and CVD risk. Prior to beginning the study, a workshop was held to train the field staff about the anthropometric measurements. The measurements were taken by one observer each for males and females and the intra- and inter-observer variation was less than $10 \%$. Study protocol and data collection procedures were standardized, calibrated equipments used at both sites, and all research assistants were trained at AIIMs and monitored during the study period.

Demographic profile Comprised of age, gender, marital status, education, employment status, income, and personal and family history of diabetes and chronic diseases.

Anthropometrics profile Height, weight, waist and hip circumference.

Fasting blood glucose and serum insulin test Venous blood sample was obtained after an overnight fast of at least $8 \mathrm{~h}$ for fasting plasma glucose (FPG). Subjects were diagnosed to have diabetes if FPG was $>=126 \mathrm{mg} \%$. Plasma insulin was measured using the Radio Immunoassay procedure (RIA; Linco Research, Inc., St. Louis, MO), and glycosy- 
lated hemoglobin $(\mathrm{HbA} 1 \mathrm{c})$ was measured using the Thiobarbituric acid method.

Serum lipids Serum levels of total cholesterol, triglycerides and HDL-c were estimated using commercially available reagent kits (Randox Laboratory, San Francisco, CA, USA) on a semi-automated analyzer (das srl, palombara, Sabina, Italy). Value of LDL-c was calculated using the Friedewald's equation.

Definitions Overweight and obesity was defined as BMI $\geq 23 \mathrm{~kg} / \mathrm{m}^{2}$ and $\geq 25 \mathrm{~kg} / \mathrm{m}^{2}$ respectively [25]. Abdominal obesity was defined using the cut-off points of waist circumference (WC) as defined by NCEP, ATP III and also according to the Asian Indians and WHO Asian Pacific Guidelines specific cut-off points [26]. High waist-to-hip circumference ratio (W-HR) was defined as $>0.90$ in males and $>0.80$ in females [27]. Diabetes was labelled if FPG was $>=126 \mathrm{mg} \%$ and/or a self-reported admission to the question "Have you ever been told by a doctor or health professional that you have diabetes or are on treatment for diabetes". Hypertension was defined as blood pressure $>140$ / $90 \mathrm{mmHg}$ and/or self-reported admission for the question "Have you ever been told by a doctor or health professional that you have hypertension or high blood pressure?" Subjects were classified as the MetS according to the National Cholesterol Education Program, Adult Treatment Panel III (NCEP, ATP III criteria): (1) WC, men $>102 \mathrm{~cm}$, women $>88 \mathrm{~cm}$; (2) triglyceride level $\geq 150 \mathrm{mg} / \mathrm{dL}$; (3) HDL cholesterol (HDL-C), men, $<40 \mathrm{mg} / \mathrm{dL}$, women, $50 \mathrm{mg} / \mathrm{dL}$; (4) blood pressure $\geq 130 / 85 \mathrm{mmHg}$ or known treatment for hypertension; and (5) fasting glucose level of $\geq 100 \mathrm{mg} / \mathrm{dL}$ or known treatment for diabetes. For each criterion, subjects received a score of 1 if present or 0 if absent, therefore allowing a range of $0-5$. A score of $\geq 3$ indicated MetS. International Diabetes Federation (IDF) criteria: central obesity for South Asians (WC, men $>90 \mathrm{~cm}$, women $>80 \mathrm{~cm}$ ), plus any two of the following four criteria: (1) triglyceride level $\geq 150 \mathrm{mg} / \mathrm{dL}$; (2) HDL-C, men $<40 \mathrm{mg} / \mathrm{dL}$, women $<50 \mathrm{mg} / \mathrm{dL}$; (3) blood pressure $\geq 130 / 85 \mathrm{mmHg}$ or known treatment for hypertension; and (4) fasting glucose level of $\geq 100 \mathrm{mg} / \mathrm{dL}$ or known treatment for diabetes. For each criterion, subjects received a score of 1 if present or 0 if absent, therefore allowing a range of $0-5$.

High-sensitivity C-reactive protein Elevated level of hsCRP was defined as $>1.0 \mathrm{mg} / \mathrm{dL}$ [28].

Statistical analysis

The first stage of analysis was to assess normal distribution of variables, descriptive statistics and differences by rural and urban Indians and data expressed as mean (SD) and proportions of the sample. The prevalence and mean (SD) of obesity, abdominal obesity, T2DM and the MetS was determined for rural and urban subjects. Analysis of Covariance (ANCOVA) (adjusted for age since there was difference in age distribution between the two groups) was used to compute all indicators. All analyses were done with the SPSS system (version 17.0). The sample size was based on power calculations for an unadjusted pair wise comparison of MetS and T2DM between rural and urban Indians. The power was set to $80 \%$ with a goal to detect differences in mean for our primary outcomes (type 1 error rate of 0.05 , two-tailed significance tests). Calculations indicated that 956 participants would provide over $80 \%$ power to detect important rural urban differences in MetS, T2DM and CVD risk factors.

\section{Results}

Demographic \& socioeconomic characteristics

The mean age was $39.5 \pm 13.9 \mathrm{y}, 18-88 \mathrm{y}$ (rural) and $42.6 \pm$ 11.8 y $18-77$ y (urban). The majority of respondents $(>75 \%)$ were married. Level of education varied between sites with $84.7 \%$ of rural Indians and $53.5 \%$ of urban Indians reporting a high school diploma or below. The modal income was $\geq \$ 200 /$ month for urban Indians and $<\$ 25 /$ month for rural Indians. However, $86 \%$ of rural Indians and $9 \%$ of urban Indians had income below Rs $3,500 /$ month (approximately $\$ 70.00$ ). The majority of urban and rural Indians were employed or self-employed (56\% and $53 \%$ respectively); $37 \%$ and $33 \%$ of urban and rural respondents were homemakers. Twenty four percent of urban respondents and $19 \%$ of rural respondents reported a family history of diabetes (includes siblings and parents). Thirty percent of rural Indians and 28\% of urban Indians used some form of tobacco (sometimes or always; cigarettes, beedi, gudka, snuff, and tobacco with Betel leaves). Significantly more rural women $(20 \%)$ used tobacco than urban women (5.2\%).

Prevalence of pre-diabetes and diabetes

Urban Indians had significantly higher rate of diabetes and pre-diabetes ( $p=.002$ and .008 respectively). Among the urban Indians, $22 \%$ of the respondents had pre-diabetes (Table 1) and $13.6 \%$ had T2DM (11.2\% with known diabetes and $2.4 \%$ with undiagnosed diabetes). Approximately one-fifth $(17.4 \%)$ of the T2DM patients did not know they had the disease; $50 \%$ and $16.6 \%$ of the undiagnosed cases had $\mathrm{HbA} 1 \mathrm{c}$ greater than 7.0 and $8.0 \%$, respectively. The prevalence of pre-diabetes and diabetes in the rural sample was $12.5 \%$ and $8.4 \%$ (6.3\% with known 
Table 1 Prevalence of diabetes and pre-diabetes in rural and urban Indians

\begin{tabular}{|c|c|c|c|c|c|}
\hline \multirow[t]{2}{*}{ Group } & \multicolumn{2}{|c|}{ Urban Indians in New Delhi } & \multicolumn{2}{|c|}{ Rural Indians in Tamil Nadu } & \multirow{2}{*}{$\begin{array}{l}\text { Urban rural difference } \\
\chi^{2} \text { value ( } p \text {-value) }\end{array}$} \\
\hline & $\begin{array}{l}(n=508) \\
\text { Prevalence } \\
(\% \text { frequency })\end{array}$ & $\begin{array}{l}(n=508) \\
\text { Blood glucose } \\
\text { Mean (SD) }\end{array}$ & $\begin{array}{l}(n=574) \\
\text { Prevalence } \\
(\% \text { frequency })\end{array}$ & $\begin{array}{l}(n=574) \\
\text { Blood glucose } \\
\text { Mean (SD) }\end{array}$ & \\
\hline Normoglycemia & $64.6(328)$ & $84.6(9.3)$ & $79.1(450)$ & $82.7(10.1)$ & $2.56(.011)$ \\
\hline Prevalence. of pre-diabetes & $21.9(111)$ & $108.2(8.2)$ & $12.5(71)$ & $105.3(5.0)$ & $2.67(.008)$ \\
\hline \multicolumn{6}{|l|}{ Gender } \\
\hline Males & $25.9(66)$ & $107.6(6.9)$ & $13.6(24)$ & $105.3(5.76)$ & $11.40(.001)$ \\
\hline Females & $17.8(45)$ & $108.9(9.7)$ & $12.0(47)$ & $105.2(4.6)$ & \\
\hline \multicolumn{6}{|l|}{ Age groups } \\
\hline $18-29$ years & $13.5(15)$ & $107.6(3.3)$ & $17.1(12)$ & $103.2(2.3)$ & $0.73(.692)$ \\
\hline $30-39$ years & $27.9(31)$ & $109.5(7.2)$ & $24.3(17)$ & $105.1(3.9)$ & \\
\hline $40-49$ years & $31.5(35)$ & $107.5(7.5)$ & $31.4(22)$ & $105.9(6.4)$ & \\
\hline $50-59$ years & $18.0(20)$ & $108.5(4.5)$ & $14.3(10)$ & $105.6(5.1)$ & \\
\hline$\geq 60$ years & $9.0(10)$ & $109.6(7.6)$ & $12.9(9)$ & $107.1(5.5)$ & \\
\hline Prevalence. of diabetes & $13.6(69)$ & $144.2(46.3)$ & $8.4(48)$ & $180.7(76.7)$ & $3.19(.002)$ \\
\hline Known diabetes & $11.3(57)$ & $142.6(47.1)$ & $6.3(36)$ & $182(78.9)$ & \\
\hline Undiagnosed diabetes & $2.4(12)$ & $152.2(43.5)$ & $2.1(12)$ & $174.4(72.3)$ & \\
\hline \multicolumn{6}{|l|}{ Gender } \\
\hline Males & $13.3(34)$ & $141.0(46.8)$ & $10.4(18)$ & $199.4(94.2)$ & $1.59(.207)$ \\
\hline Females & $13.8(35)$ & $147.3(46.3)$ & $7.6(30)$ & $169.4(63.1)$ & \\
\hline \multicolumn{6}{|l|}{ Age groups } \\
\hline $18-29$ years & $1.4(1)$ & $157.0(0)$ & $4.2(2)$ & $103.5(31.8)$ & $1.17(.882)$ \\
\hline $30-39$ years & $14.5(10)$ & $124.5(55.2)$ & $14.6(7)$ & $111.4(46.2)$ & \\
\hline $40-49$ years & $30.4(21)$ & $132.6(26.9)$ & $25.0(12)$ & $159.5(59.4)$ & \\
\hline $50-59$ years & $29.0(20)$ & $155.8(62.2)$ & $29.3(14)$ & $185.5(52.1)$ & \\
\hline$\geq 60$ years & $24.6(17)$ & $144.3(46.3)$ & $27.1(13)$ & $206.3(84.3)$ & \\
\hline
\end{tabular}

diabetes and $2.1 \%$ with undiagnosed diabetes) respectively. One-fourth (25.0\%) of the T2DM individuals were unaware they had the disease; $91.7 \%$ and $49.8 \%$ of the undiagnosed cases had HbA1c greater than 7.0 and $8.0 \%$ respectively.

Mean HbA1c was significantly higher among rural Indians with T2DM than urban Indians $(p<.001)$. Although no gender differences were noted in rural areas, urban males $(7.27 \pm 1.24)$ had poor glycemic control $(p=0.90)$ as compared to their female peers $(6.80 \pm 0.99)$. The prevalence of diabetes in different age groups showed an increase with age while the prevalence of IFG did not change $(p<.001)$.

Obesity, hypertension, and the metabolic syndrome

The mean BMI $\left(\mathrm{kg} / \mathrm{m}^{2}\right)$ was $24.7 \pm 4.8$ and $21.3 \pm 4.0$ for urban and rural respondents respectively. According to the Asian criteria, $16 \%$ of urban Indians and $14 \%$ of the rural Indians were overweight and $50 \%$ of urban Indians and $18 \%$ of rural Indians were obese. The mean WC was $89.6 \pm$ 13.0 and $74.8 \pm 11.3$ for urban and rural Indians respectively
(Table 2). Using WC criterion, 66\% of urban respondents and $24 \%$ of rural respondents had central obesity, significantly higher among females $(76 \%, 27 \%)$ than males $(57 \%$, $17 \%$ ) in both urban and rural areas. The mean WHR was $0.94 \pm .09$ and $0.84 \pm .08$ for urban and rural respondents respectively; WHR was elevated in $40 \%$ of urban $\& 16 \%$ of rural males and $43 \%$ of urban $\& 36 \%$ of rural females. Men and women living in urban areas had higher BMI, WC and $\mathrm{W}-\mathrm{HR}$, and were more likely to be overweight or obese than rural subjects (Table 3).

Prevalence of pre-hypertension (Urban, 38\% systolic \& 44\% diastolic; Rural, 30\% systolic \& 20\% diastolic) and hypertension (Urban, 20\% systolic and 24\% diastolic; Rural 9\% systolic and 7\% diastolic) was significantly higher $(p=.001)$ among urban Indians than rural Indians, and increased with age $(p=.001)$. There was a linear (significant) increase in systolic and diastolic blood pressure with the increase in fasting blood glucose levels. Approximately one-third (30.3\%, males, 34.5\%, females, $25.8 \% ; p=0.03$ ) of urban and $12.0 \%$ (males, $10.2 \%$, females, $12.8 \%$ ) of rural subjects were hypertensive. The 
Table 2 Metabolic syndrome among rural and urban Indians by ATP/ NCEP III and IDF criteria

\begin{tabular}{|c|c|c|c|c|c|c|c|}
\hline \multirow[t]{2}{*}{ Metabolic syndrome } & \multirow[t]{2}{*}{ Indicator components } & \multicolumn{2}{|c|}{ Total sample $(n=508)$} & \multirow{2}{*}{$\begin{array}{l}\text { Male } \\
(n=255)\end{array}$} & \multirow{2}{*}{$\begin{array}{l}\text { Female } \\
(n=253)\end{array}$} & \multirow{2}{*}{$\begin{array}{l}\text { Gender difference }^{\mathrm{a}} \\
T \text {-value ( } p \text {-value) }\end{array}$} & \multirow{2}{*}{$\begin{array}{l}\text { Rural-urban difference } \\
T \text {-value ( } p \text {-value) }\end{array}$} \\
\hline & & Mean (SD) & $\%$ at risk & & & & \\
\hline Urban Indians & & & & Male & Female & Urban Indians & \\
\hline Blood pressure $^{\mathrm{b}}$ & $\geq 130 / 85 \mathrm{mmHg}$ & $123 / 82$ & $42.9 \%$ & $45.1 \%$ & $40.6 \%$ & $9.98(0.327)$ & $14.40(<.001)$ \\
\hline $\mathrm{HDL}^{\mathrm{c}}$ & $\leq 40 \mathrm{mg} / \mathrm{dl}$ in $\mathrm{M}$ & $46.93(5.7)$ & $40.0 \%$ & $4.7 \%$ & $68.0 \%$ & $19.67(<.001)$ & $15.56(<.001)$ \\
\hline $\mathrm{HDL}^{\mathrm{c}}$ & $\leq 50 \mathrm{mg} / \mathrm{dl}$ in $\mathrm{W}$ & & & & & & \\
\hline $\mathrm{FBG}^{\mathrm{d}}$ & $\geq 100 \mathrm{mg} / \mathrm{dl}$ & $97.82(28.1)$ & $35.6 \%$ & $39.2 \%$ & $31.9 \%$ & $1.72(0.085)$ & $1.82(.068)$ \\
\hline Serum triglyceride ${ }^{\mathrm{e}}$ & $\geq 150 \mathrm{mg} / \mathrm{dl}$ & $146.50(65.3)$ & $40.0 \%$ & $43.1 \%$ & $36.8 \%$ & $1.46(0.143)$ & $6.37(<.001)$ \\
\hline Waist circumference $^{\mathrm{f}}$ & $\geq 102 \mathrm{~cm}$ in $\mathrm{M}$ & $89.61(13.1)$ & $38.6 \%$ & $18.4 \%$ & $58.9 \%$ & $10.27(<.001)$ & $15.52(<.001)$ \\
\hline Waist circumference $^{\mathrm{f}}$ & $\geq 88 \mathrm{~cm}$ in $\mathrm{W}$ & & & & & & \\
\hline Waist circumference ${ }^{\mathrm{g}}$ & $\geq 90 \mathrm{~cm}$ in $\mathrm{M}$ & $74.75(11.4)$ & $66.3 \%$ & $56.5 \%$ & $76.3 \%$ & $4.82(<.001)$ & $20.00(<.001)$ \\
\hline Waist circumference ${ }^{\mathrm{g}}$ & $\geq 80 \mathrm{~cm}$ in $\mathrm{W}$ & & & & & & \\
\hline $\mathrm{NCEP}^{\mathrm{b}, \mathrm{c}, \mathrm{d}, \mathrm{e}, \mathrm{f}}$ & Met $\mathrm{S} \%$ & $30.8 \%$ & & $17.6 \%$ & $44.2 \%$ & $7.53(<.001)$ & $87.48(<.001)$ \\
\hline $\operatorname{IDF}^{b, c, d, f, g}$ & & $39.2 \%$ & & $30.6 \%$ & $47.8 \%$ & $4.03(<.001)$ & $122.09(<.001)$ \\
\hline Rural Indians & & & & $\begin{array}{l}\text { Male } \\
(n=177)\end{array}$ & $\begin{array}{l}\text { Female } \\
(n=397)\end{array}$ & & \\
\hline Blood pressure ${ }^{\mathrm{b}}$ & $\geq 130 / 85 \mathrm{mmHg}$ & $115 / 73$ & $18.6 \%$ & $16.4 \%$ & $19.6 \%$ & $0.92(0.355)$ & \\
\hline $\mathrm{HDL}^{\mathrm{c}}$ & $<40 \mathrm{mg} / \mathrm{dl}$ in $\mathrm{M}$ & $52.04(5.0)$ & $27.9 \%$ & $0 \%$ & $40.5 \%$ & $10.95(<.001)$ & \\
\hline $\mathrm{HDL}^{\mathrm{c}}$ & $<50 \mathrm{mg} / \mathrm{dl}$ in $\mathrm{W}$ & & & & & & \\
\hline $\mathrm{FBG}^{\mathrm{d}}$ & $\geq 100 \mathrm{mg} / \mathrm{dl}$ & $95.42(47.6)$ & $21.2 \%$ & $24.3 \%$ & $19.8 \%$ & $1.21(0.225)$ & \\
\hline Serum triglyceride ${ }^{\mathrm{e}}$ & $\geq 150 \mathrm{mg} / \mathrm{dl}$ & 121.17 (64.9) & $22.8 \%$ & $25.4 \%$ & $21.6 \%$ & $1.01(0.311)$ & \\
\hline Waist circumference ${ }^{\mathrm{f}}$ & $\geq 102 \mathrm{~cm}$ in $\mathrm{M}$ & $74.75(11.4)$ & $7.7 \%$ & $3.4 \%$ & $9.6 \%$ & $2.58(0.010)$ & \\
\hline Waist circumference ${ }^{f}$ & $\geq 88 \mathrm{~cm}$ in $\mathrm{W}$ & & & & & & \\
\hline Waist circumference ${ }^{\mathrm{g}}$ & $\geq 90 \mathrm{~cm}$ in $\mathrm{M}$ & $74.75(11.4)$ & $23.9 \%$ & $16.9 \%$ & $27.0 \%$ & $2.77(0.006)$ & \\
\hline Waist circumference ${ }^{\mathrm{g}}$ & $\geq 80 \mathrm{~cm}$ in $\mathrm{W}$ & & & & & & \\
\hline $\mathrm{NCEP}^{\mathrm{b}, \mathrm{c}, \mathrm{d}, \mathrm{e}, \mathrm{f}}$ & Met S\% & $8.6 \%$ & & $4.6 \%$ & $10.4 \%$ & $4.48(<0.001)$ & \\
\hline $\mathrm{IDF}^{\mathrm{b}, \mathrm{c}, \mathrm{d}, \mathrm{f}, \mathrm{g}}$ & & $10.5 \%$ & & $6.2 \%$ & $12.3 \%$ & $2.49(0.013)$ & \\
\hline
\end{tabular}

NCEP Criteria: metabolic syndrome is present if any three indicators ${ }^{\mathrm{b}, \mathrm{c}, \mathrm{d}, \mathrm{e}, \mathrm{f}}$ meet the criterion

IDF Criteria: Metabolic syndrome is present if central obesity and any two indicators ${ }^{\mathrm{b}, \mathrm{c}, \mathrm{d}, \mathrm{f}, \mathrm{g}}$ meet the criterion

${ }^{a}$ Significant difference between groups based on Student $t$-test

${ }^{\mathrm{b}-\mathrm{g}}$ Presents indicators of Metabolic Syndrome as defined by NCEP and IDF

${ }^{\mathrm{b}}$ Blood Pressure $\geq 130 / 85 \mathrm{mmHg}$

${ }^{\mathrm{c}} \mathrm{HDL}<40 \mathrm{mg} / \mathrm{dl}$ in Men and $<50 \mathrm{mg} / \mathrm{dl}$ in Women

${ }^{\mathrm{d}} \mathrm{FBG} \geq 100 \mathrm{mg} / \mathrm{dl}$

${ }^{\mathrm{e}}$ Serum triglyceride $\geq 150 \mathrm{mg} / \mathrm{dl}$

${ }^{\mathrm{f}}$ Waist Circumference $\geq 88 \mathrm{~cm}$ in Women and $\geq 102 \mathrm{~cm}$ in Men

${ }^{\mathrm{g}}$ Waist Circumference $\geq 80 \mathrm{~cm}$ in Women and $\geq 90 \mathrm{~cm}$ in Men

prevalence of the MetS was $30.8 \%$ and $8.6 \%$ among the urban and rural respondents respectively using the NCEP, ATP III definition, and $39.2 \%$ and $10.5 \%$ using the IDF definition (Table 2). The prevalence of the MetS is significantly higher among urban females $(44.2 \%$ and $47.8 \%$ using NCEP, ATP III and IDF criteria, respectively) than males $(39.2 \%$ and $47.8 \%$, respectively); a similar pattern was noted among rural males and females (Table 2). In urban Asian Indians, the prevalence rates were higher for blood pressure (42.9\%), serum triglyceride
(40\%), and low levels of HDL-C (40\%; higher among females than males), and abdominal obesity (66.3\%). The rates were lower in the rural Indians in all the individual MetS criteria, with the highest abnormalities noted in low levels of HDL-C (27.9\%; higher among females than males), triglyceride (22.8\%), and abdominal obesity (23.9\%). These results show the prevalence of the MetS is significantly higher among urban Indians than rural Indians with significant gender differences in two of the five criteria (cholesterol and abdominal obesity). Both 


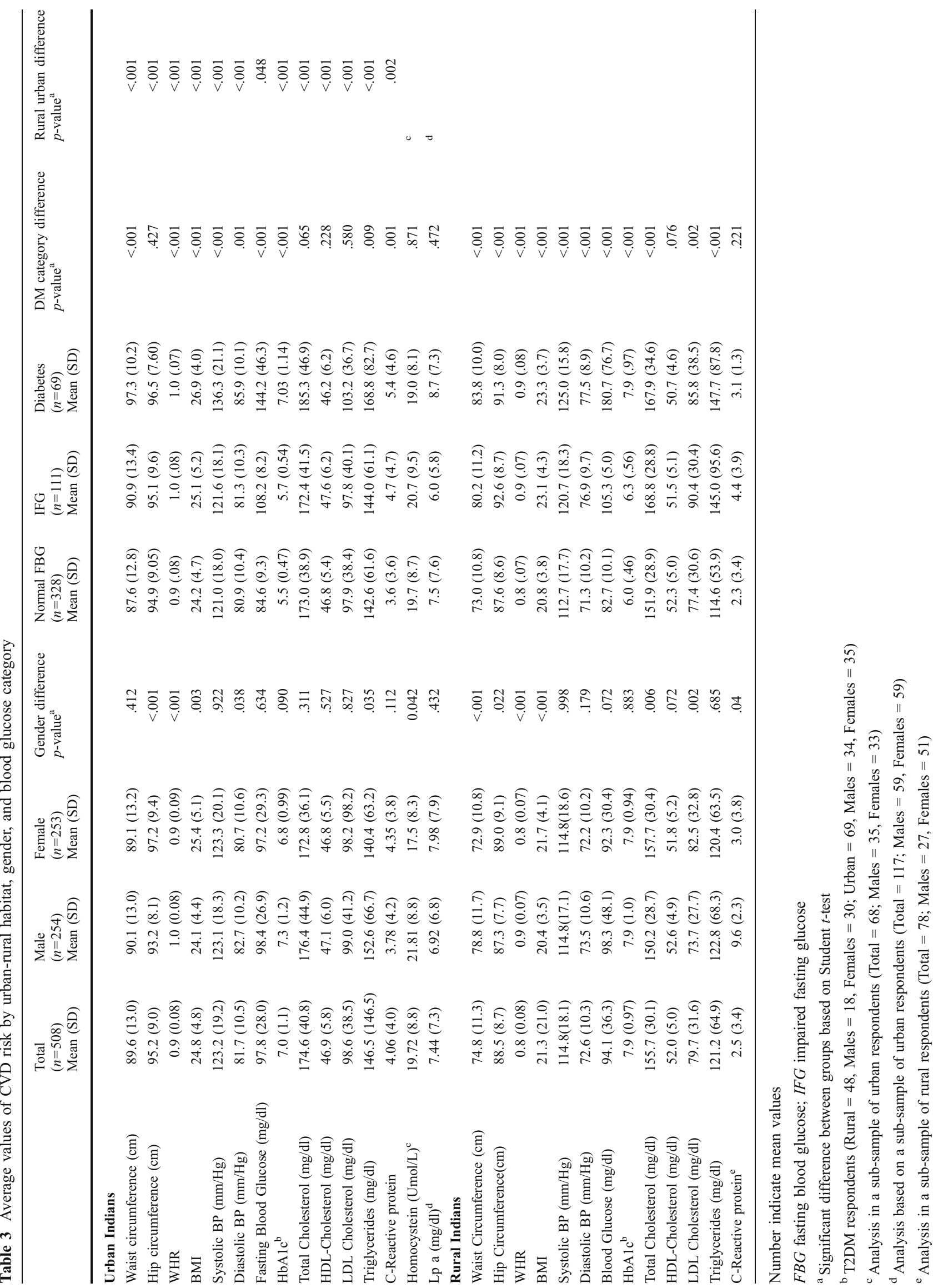


urban and rural females had significantly higher risk for abdominal obesity and low levels of HDL-C than their male peers.

C-reactive protein, other cardiovascular disease risk factors and relationship to glycemia

There was a high prevalence of total cholesterol $(24.8 \%)$, high LDL-C $(20.3 \%,>130 \mathrm{mg} / \mathrm{dl})$, and hs-CRP (77\%) in the urban respondents. Abnormal levels were lower among rural Indians: 9.5\% total cholesterol, 7.8\% high LDL, and $50 \%$ high hs-CRP. Urban males had significantly higher triglyceride levels than urban females while rural females had higher cholesterol and LDL cholesterol than rural males. Clinical and bioclinical parameters were significantly different among normoglycemic, IFG, and T2DM individuals in both rural and urban areas (Table 3). The rates of general and abdominal obesity, elevated hs-CRP, increased systolic and diastolic blood pressure and low HDL-C were higher among T2DM respondents compared to normoglycemic and IFG urban and rural Indians. Homocysteine levels (measured only among urban respondents) was higher among males than females ( $p=.04)$. There was a step-wise worsening of all metabolic parameters progressing from normal to IFG to T2DM, suggesting that Indians progress through the stages of dyglycemia to overt diabetes in a similar manner in both rural and urban India.

\section{Discussion}

This is the first comprehensive study to investigate T2DM, obesity, the MetS, hs-CRP and other CVD risk factors in a large population of urban and rural Indians using similar and standardized field measurements. The prevalence of T2DM (13.6\%) and IFG (21.9\%) and the MetS was high in urban areas, similar to other reports from other regions of India $[5,6,10,18,29,30]$. The dysmetabolic phenotype of urban inhabitants is due to rapid nutrition transition, physical inactivity, and stress. The changing dietary profile over the last decade includes increased consumption of non-traditional 'westernized' foods and 'energy-dense' Asian Indian foods, more so in urban areas.

Interestingly, our study shows one of the highest prevalence of diabetes among all rural surveys in India [3, 21, 31]. Chow et al. [22] showed higher prevalence of T2DM in villages of south east India (13.2\%). However, the authors used capillary blood glucose test and sample population consisted of people $>30 \mathrm{y}$ age (as opposed to $>18 \mathrm{y}$ in the current study). A high prevalence of diabetes (9.2\%: [95\% CI 8-10.5]) was shown in peri-urban villages in South India [32], however, self-reported diabetes ( 3\%) [33] and mean levels of fasting blood glucose and lipids
[34] were similar in rural and peri-urban areas of north India. High and increasing prevalence of diabetes and other CVD risk factors in rural and urban residents is due to decreased consumption of traditional frugal diets, less labor-intensive work due to mechanization and commuting, and increased obesity $[35,36]$.

Worldwide studies have shown that Asian Indians develop diabetes a decade earlier than other ethnic groups [37]. Clustering of risk factors and diabetes are clearly evident even at a young age in the present study; $29 \%$ and $13.4 \%$ of the sample showing glucose intolerance (diabetes or pre-diabetes) in urban and rural areas, respectively in 1839 y age group. Here again, the prime reason is that change from traditional diets to energy-dense, high saturated fat diets is occurring more rapidly and relentlessly in children and young adults. Importantly, the prevalence of prediabetes is highest in young urban and rural dwellers in this age group, providing opportunity for early application of preventive strategies. Further, as can be clearly seen from Table 3, most of these people with pre-diabetes are converting to diabetes, thus increasing prevalence of diabetes in later decades, with simultaneous decrease in the prevalence of pre-diabetes.

A notable feature was higher prevalence of the MetS in women as compared to men in both urban and rural areas, an observation reported from other regions of India [38]. This is primarily due to high prevalence of abdominal obesity and low levels of HDL-C in women. Two factors contribute to such a phenotype; first, largely sedentary lifestyle of females in India [39] and second, the inability to shed weight gained post-pregnancy contributed by inactivity and imbalanced diets during perinatal and postnatal periods. In rural western India, women who gained more weight during and after pregnancy were sedentary and had thicker skinfolds and showed more tendency for hyperglycemia after pregnancy [40]. Interestingly, in the current study, despite higher prevalence of the MetS in women, the prevalence of diabetes was almost similar to men. It is likely that if women with the MetS continue with the current imbalanced lifestyle, conversion to diabetes may occur rapidly, and thus prevalence of diabetes may also rise later.

High prevalence of generalized and abdominal obesity is clearly a precursor for development of cluster of risk factors comprising the MetS, and also increase subclinical inflammation. Typical Asian Indian phenotype of obesity consists of high body fat for comparatively low BMI, high subcutaneous and intra-abdominal fat, and ectopic fat deposition in liver [4]. Such high adipose tissue mass seen early in life, contribute importantly to the dysregulation of glucose-insulin-lipid metabolism.

Another interesting observation was elevated hs-CRP in urban and rural Indians. Among urban Indians, the average levels fall in the high cardiovascular risk category $(>1)$ and 
is a concern given it mediates the relationship between body fat, other inflammatory markers, and coronary artery disease [41, 42]. Moreover, hs-CRP levels were higher in females, in both urban and rural areas. High levels of hsCRP in Asian Indians may be due to the following two factors; excess adiposity, and second, possibly induced by subclinical infections. Whether these high levels of hs-CRP relate to excess cardiovascular risk in Asian Indians remains to be demonstrated.

High prevalence of pre-diabetes in urban and rural areas provides us opportunity to pursue lifestyle-based primary prevention strategies. Poor glycemic control due to late diagnosis and poor medical care among rural subjects who were mostly illiterates and unaware of diabetes and its consequences suggest that health education, early diagnosis and effective management are especially needed in rural areas of India. We have recently reported successful reduction of key risk factors (WC and blood pressure) and fasting blood glucose levels among pre-diabetic youth by $17 \%$, pre-diabetic adults by $11 \%$, and adults with T2DM by $25 \%$ in a 7 month community-based intervention in rural South India [11]. Intervention improved intake of fiber and protein besides lowering obesity in youth and adults.

In conclusion, there was a high prevalence of diabetes, MetS, obesity and low HDL in urban communities as compared to rural areas along with elevated levels of hsCRP and homocysteine. There was a progressive worsening of all metabolic parameters from normoglycemic to IFG to T2DM among respondents that provide a firm basis for tailored prevention and intervention programs, an economically beneficial feature in such resourceconstrained settings.

\section{References}

1. Wild S, Roglic G, Green A, Sicree R, King H. Global prevalence of diabetes: estimates for the year 2000 and projections for 2030 . Diab Care. 2004;27:1047-53.

2. King H, Aubert RE, Herman WH. Global burden of diabetes, 1995-2025: prevalence, numerical estimates, and projections. Diab Care. 1998;21:1414-31.

3. Ramachandran A, Snehalatha C, Baskar AD, Mary S, Kumar CK, Selvam S, et al. Temporal changes in prevalence of diabetes and impaired glucose tolerance associated with lifestyle transition occurring in the rural population in India. Diabetologia. 2004; 47:860-5.

4. Misra A, Khurana L. Obesity and the metabolic syndrome in developing countries. J Clin Endocrinol Metab. 2008;93(11 Suppl 1):S9-S30.

5. Gupta R, Sarna M, Thanvi J, Sharma V, Gupta VP. Fasting glucose and cardiovascular risk factors in an urban population. $\mathrm{J}$ Assoc Physicians India. 2007;55:705-9.

6. Sadikot SM, Nigam A, Das S, Bajaj S, Zargar AH, Prasannakumar KM, et al. The burden of diabetes and impaired glucose tolerance in India using the WHO 1999 criteria: prevalence of diabetes in India study (PODIS). Diabetes Res Clin Pract. 2004;66:301-7.

7. Mohan A, Sandeep S, Deepa R, Vimaleswaran K, Farooq S, Mohan V. Visceral and central abdominal fat and anthropometry in relation to diabetes in Asian Indians. Diab Care. 2004;27:2948-53.

8. Ramachandran A, Snehalatha C, Satyavani K, Sivasankari S, Vijay V. Metabolic syndrome in urban Asian Indian adults-a population study using modified ATP III criteria. Diabetes Res Clin Pract. 2003;60:199-204.

9. Mahadik SR, Deo SS, Mehtalia SD. Increased prevalence of metabolic syndrome in non-obese asian Indian-an urban-rural comparison. Metab Syndr Relat Disord. 2007;5:142-52.

10. Ramachandran A, Snehalatha C, Kapur A, Vijay V, Mohan V, Das $\mathrm{AK}$, et al. High prevalence of diabetes and impaired glucose tolerance in India: National Urban Diabetes Survey. Diabetologia. 2001;44:1094-101.

11. Banerji MA, Faridi N, Atluri R, Chaiken RL, Lebovitz HE. Body composition, visceral fat, leptin, and insulin resistance in Asian Indian men. J Clin Endocrinol Metab. 1999;84:137-44.

12. McKeigue PM, Pierpoint T, Ferrie JE, Marmot MG. Relationship of glucose intolerance and hyperinsulinaemia to body fat pattern in south Asians and Europeans. Diabetologia. 1992;35:785-91.

13. McKeigue PM. Metabolic consequences of obesity and body fat pattern: lessons from migrant studies. Ciba Found Symp. 1996;201:54-64. discussion 64-7, 188-93.

14. Whincup PH, Gilg JA, Papacosta O, Seymour C, Miller GJ, Alberti $\mathrm{KG}$, et al. Early evidence of ethnic differences in cardiovascular risk: cross sectional comparison of British South Asian and white children. BMJ. 2002;324:635.

15. Zargar AH, Khan AK, Masoodi SR, Laway BA, Wani AI, Bashir MI, et al. Prevalence of type 2 diabetes mellitus and impaired glucose tolerance in the Kashmir Valley of the Indian subcontinent. Diabetes Res Clin Pract. 2000;47:135-46.

16. Ramachandran A, Snehalatha C, Satyavani K, Sivasankari S, Vijay V. Type 2 diabetes in Asian-Indian urban children. Diab Care. 2003;26:1022-5.

17. Misra A, Pandey RM, Devi JR, Sharma R, Vikram NK, Khanna $\mathrm{N}$. High prevalence of diabetes, obesity and dyslipidaemia in urban slum population in northern India. Int J Obes Relat Metab Disord. 2001;25:1722-9.

18. Mohan V, Shanthirani S, Deepa R, Premalatha G, Sastry NG, Saroja R. Intra-urban differences in the prevalence of the metabolic syndrome in southern India-the Chennai Urban Population Study (CUPS No. 4). Diabet Med. 2001;18:280-7.

19. Iyer SR, Iyer RR, Upasani SV, Baitule MN. Diabetes mellitus in Dombivli-an urban population study. J Assoc Physicians India. 2001;49:713-6.

20. Bai PV, Krishnaswami CV, Chellamarippan M, Kumar GV, Subramaniam JR, Srivatwa A, et al. Prevalence of diabetes in the young in south India. Indian Pediatr. 1995;32:1173-6.

21. Balagopal P, Kamalamma N, Patel TG, Misra R. A communitybased diabetes prevention and management education program in a rural village in India. Diab Care. 2008;31:1097-104.

22. Chow CK, Raju PK, Raju R, Reddy KS, Cardona M, Celermajer DS, et al. The prevalence and management of diabetes in rural India. Diab Care. 2006;29:1717-8.

23. Rao PV, Ushabala P, Seshiah V, Ahuja MM, Mather HM. The Eluru survey: prevalence of known diabetes in a rural Indian population. Diabetes Res Clin Pract. 1989;7:29-31.

24. Lemeshow S, Stroh GJ. Sampling techniques for evaluating health parameters in developing countries. Washington: National Academy Press; 1988.

25. International Association for the Study of Obesity and International Obesity Task Force. The Asia-Pacific Perspective. Redefining 
Obesity and its Treatment. International Diabetes Institute: Western Pacific Region, Health Communications Australia Pvt Ltd., 2000.

26. Banerjee D, Misra A. Does using ethnic specific criteria improve the usefulness of the term metabolic syndrome? Controversies and suggestions. Int J Obes Lond. 2007;31:1340-9.

27. Chamukuttan S, Viswanathan V, Ramachandran A. Cut-off values for normal anthropomatric variables in Asian Indian adults. Diab Care. 2003;26:1380-4.

28. Chandalia M, Cabo-Chan Jr AV, Devaraj S, Jialal I, Grundy SM, Abate N. Elevated plasma high-sensitivity C-reactive protein concentrations in Asian Indians living in the United States. J Clin Endocrinol Metab. 2003;88:3773-6.

29. Boddula R, Yadav S, Bhatia V, Genitta G, Pandey D, Kumar A, et al. High prevalence of type 2 diabetes mellitus in affluent urban Indians. Diabetes Res Clin Pract. 2008;81(2):e4-7.

30. Menon VU, Kumar KV, Gilchrist A, Sugathan TN, Sundaram KR, Nair V, et al. Prevalence of known and undetected diabetes and associated risk factors in central Kerala-ADEPS. Diabetes Res Clin Pract. 2006;74:289-94.

31. Sadikot SM, Nigam A, Das S, Bajaj S, Zargar AH, Prasannakumar $\mathrm{KM}$, et al. The burden of diabetes and impaired fasting glucose in India using the ADA 1997 criteria: prevalence of diabetes in India study (PODIS). Diabetes Res Clin Pract. 2004;66:293-300.

32. Ramachandran A, Mary S, Yamuna A, Murugesan N, Snehalatha C. High prevalence of diabetes and cardiovascular risk factors associated with urbanization in India. Diab Care. 2008;31:893-8.

33. Mohan V, Mathur P, Deepa R, Deepa M, Shukla DK, Menon GR, et al. Urban rural differences in prevalence of self-reported diabetes in India - the WHO-ICMR Indian NCD risk factor surveillance. Diabetes Res Clin Pract. 2008;80:159-68.

34. Nongkynrih B, Acharya A, Ramakrishnan L, Ritvik, Anand K, Shah B. Profile of biochemical risk factors for non communicable diseases in urban, rural and periurban Haryana, India. J Assoc Physicians India. 2008;56:165-70.
35. Pandey RM, Madhavan M, Misra A, Kalaivani M, Vikram NK, Dhingra V. Centiles of anthropometric measures of adiposity for 14- to 18-year-old urban Asian Indian adolescents. Metab Syndr Relat Disord. 2009;7:133-41.

36. Yajnik CS, Joglekar CV, Lubree HG, Rege SS, Naik SS, Bhat $\mathrm{DS}$, et al. Adiposity, inflammation and hyperglycaemia in rural and urban Indian men: Coronary Risk of Insulin Sensitivity in Indian Subjects (CRISIS) Study. Diabetologia. 2008;51:39-46.

37. Qiao Q, Hu G, Tuomilehto J, Nakagami T, Balkau B, BorchJohnsen K, et al. Age- and sex-specific prevalence of diabetes and impaired glucose regulation in 11 Asian cohorts. Diab Care. 2003;26:1770-80.

38. Chow CK, McQuillan B, Raju PK, Iyengar S, Raju R, Harmer JA, et al. Greater adverse effects of cholesterol and diabetes on carotid intima-media thickness in South Asian Indians: comparison of risk factor-IMT associations in two population-based surveys. Atherosclerosis. 2008;199:116-22.

39. Misra A, Vikram NK. Insulin resistance syndrome (metabolic syndrome) and obesity in Asian Indians: evidence and implications. Nutrition. 2004;20:482-91.

40. Kulkarni SR, Fall CH, Joshi NV, Lubree HG, Deshpande VU, Pasarkar RV, et al. Determinants of incident hyperglycemia 6 years after delivery in young rural Indian mothers: the Pune Maternal Nutrition Study (PMNS). Diab Care. 2007;30:2542-7.

41. Mohan V, Deepa R, Velmurugan K, Premalatha G. Association of C-reactive protein with body fat, diabetes and coronary artery disease in Asian Indians: the Chennai Urban Rural Epidemiology Study (CURES-6). Diabet Med. 2005;22:863-70.

42. Sainani GS, Karatela RA. Plasma leptin in insulin-resistant and insulin-nonresistant coronary artery disease and its association with cardio-metabolic risk factors among Asian Indians. Metab Syndr Relat Disord. 2009;7:335-40. 